Check for updates

Cite this: RSC Adv., 2018, 8, 24654

\section{An expeditious and efficient bromomethylation of thiols: enabling bromomethyl sulfides as useful building blocks $\uparrow$}

\author{
Carolina Silva-Cuevas, ${ }^{a}$ Ehecatl Paleo, ${ }^{b}$ David F. León-Rayo and J. Armando Lujan- \\ Montelongo (iD)*a
}

Received 10th May 2018

Accepted 28th June 2018

DOI: $10.1039 / \mathrm{c} 8 \mathrm{ra} 04002 \mathrm{~h}$

rsc.li/rsc-advances

\begin{abstract}
A facile and highly efficient method for the bromomethylation of thiols, using paraformaldehyde and $\mathrm{HBr} /$ $\mathrm{AcOH}$, has been developed, which advantageously minimizes the generation of highly toxic byproducts. The preparation of 22 structurally diverse $\alpha$-bromomethyl sulfides illustrates the chemo-tolerant applicability while bromo-lithium exchange and functionalization sequences, free radical reductions, and additions of the title compounds demonstrate their synthetic utility.
\end{abstract}

Heteroatom halomethylations ${ }^{1}$ have proven to be extremely useful for the generation of valuable synthetic intermediates. ${ }^{2}$ Halomethylation of thiols provides synthetically valuable chloromethylated intermediates (chloromethyl sulfides), which are typically prepared by condensation with bromochloromethane in basic media, ${ }^{3}$ or with $\mathrm{HCl}$ and a formaldehyde source (paraformaldehyde, polyoxymethylene, etc.). ${ }^{4}$ While chloromethyl sulfides have been traditionally used as alkylating reagents, the analogous bromomethyl counterparts offer superior electrophilicity, recognized since the earliest report describing their syntheses using hydrogen bromide and paraformaldehyde, ${ }^{5}$ yet they are often overlooked in this role. Moreover, the reactivity scope of bromomethyl thiol derivatives remains largely unexplored, despite a potentially broader synthetic range (e.g. for the generation of organometallics by metal-halogen exchange). ${ }^{6}$

Other methods for the generation of bromomethylated thiol derivatives consist of replacing hydrogen bromide gas with concentrated aqueous hydrobromic acid, along with a formaldehyde source (usually paraformaldehyde), ${ }^{7}$ or by using dibromomethane $^{8}$ in basic media. ${ }^{9}$ Two or three-step procedures consisting of hydroxymethylation followed by substitution have also been developed. ${ }^{10}$ A desilylative rearrangement of $\alpha$-TMS sulfides has also been used for the generation of bromomethylsulfides. ${ }^{11}$

As part of our interest in the preparation and application of structurally diverse sulfur-based building blocks, ${ }^{12}$ we

\footnotetext{
${ }^{a}$ Departamento de Quimica, Centro de Investigación y de Estudios Avanzados (Cinvestav), Av. Instituto Politécnico Nacional 2508, San Pedro Zacatenco, 07360 Ciudad de México, México.E-mail: jalujanm@cinvestav.mx

${ }^{b}$ Facultad de Ciencias, Universidad Nacional Autónoma de México, Ciudad Universitaria, 04510, Ciudad de México, México

$\dagger$ Electronic supplementary information (ESI) available: Detailed procedures and NMR data. See DOI: 10.1039/c8ra04002h
}

investigated the preparation of benzyl(bromomethyl)sulfane (2a), previously used as an olefination reagent. ${ }^{13}$ However, several attempts to prepare 2a through exposure of benzylmercaptan (1a) to paraformaldehyde and hydrobromic acid, ${ }^{7 b}$ led to a $c a$. $1.5: 1$ mixture of $2 \mathbf{a}(32 \%)$ and bis(benzylthio)methane $\mathbf{3 a}$ (21\%, Scheme 1a). Iterations of the experiment always delivered important and variable amounts of the dithioacetal by-product 3a. On the other hand, an alternate approach to the bromomethylation of a cyclohexanethiol bromomethyl derivative $\mathbf{2 b}$, using dibromomethane and $\mathrm{K}_{2} \mathrm{CO}_{3}$, resulted in trace amounts of the dithioacetal derivative $\mathbf{3 b}$ only (Scheme $1 \mathrm{~b}$ ). ${ }^{14}$

$\mathrm{HBr} / \mathrm{AcOH}$ is a convenient hydrogen bromide source that minimizes exposure to risky set-ups and has been employed as a surrogate to highly corrosive and toxic hydrogen bromide gas in numerous applications. ${ }^{15}$ Although this reagent has been used previously in the generation of bromomethyl sulfides, installation of the methylene bridge required first a Spivaloxymethylation of a mercaptan, followed by cleavage by $\mathrm{HBr} / \mathrm{AcOH} .^{16}$

Surprisingly, sequential exposure of thiols $\mathbf{1 a}$ or $\mathbf{1 b}$ to paraformaldehyde and $\mathrm{HBr} / \mathrm{AcOH},{ }^{17}$ rapidly delivered bromomethylated derivatives $\mathbf{2 a}$ and $\mathbf{2} \mathbf{b}$ with outstanding yields (Scheme

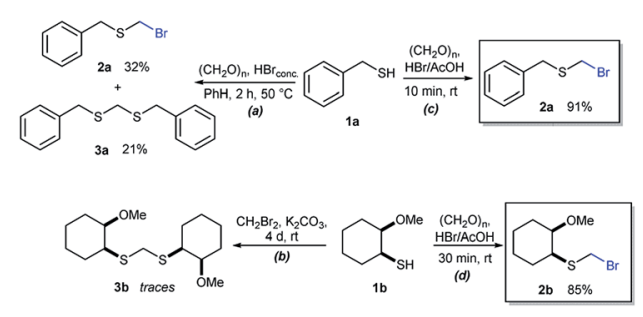

Scheme 1 Attempts for the bromomethylation of $1 \mathrm{a}$ or $1 \mathrm{~b}$ under (a) acidic or (b) basic media. (c) and (d) A highly efficient and direct approach for thiol bromomethylation (this work). 
1). The simple experimental setup and straightforward purification procedure offer methodological utility; in most cases extraction with a low-boiling point hydrocarbon such as pentane or hexanes is sufficient to recover the material in high purity $(>95 \%) .{ }^{18}$ Traces of impurities can be easily discarded through bulb-to-bulb vacuum distillation.

The reaction scope was explored with a series of structurally diverse thiols (Table 1). Aliphatic thiols yielded bromomethyl sulfides in excellent yields, although lower yielding $\mathbf{2} \mathbf{g}$ is attributed to its high volatility. $t$-Butyl bromomethyl sulfide (2i), a sterically challenging and volatile material that has been used as a synthetic equivalent of the methylmercaptan group $\left(-\mathrm{CH}_{2}-\right.$ $\mathrm{SH}){ }_{1}^{19}$ was prepared satisfactorily in $76 \%$ yield. Fluorinated bromomethyl $2 \mathrm{e}$ has been used for the preparation of fluorinated surfactants, ${ }^{\mathbf{1 0 a}, \mathbf{2 0}}$ which some exhibit antimicrobial activity. As a previous method involves a 2 -step sequence involving thiol hydroxymethylation and substitution by $\mathrm{PBr}_{3}$, our method directly delivered $2 \mathrm{e}$ in $88 \%$ yield.

Aromatic substrates $(\mathbf{2 j}-\mathbf{2 v})$ were generally high yielding. For example, (bromomethyl)(phenyl)sulfane (2j), a useful

Table 1 Thiol bromomethylation with $\mathrm{HBr} /$ paraformaldehyde ${ }^{a}$

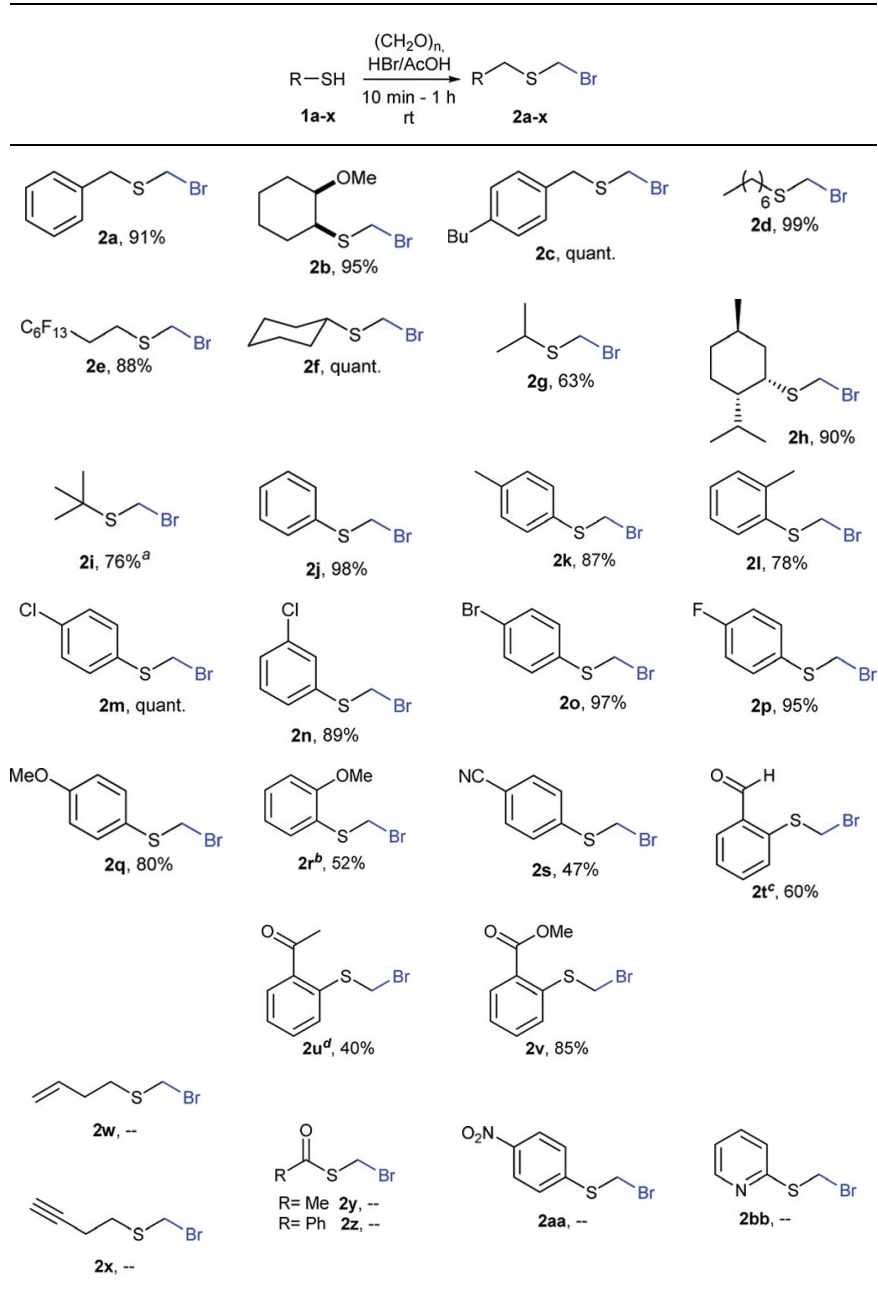

${ }^{a}$ Reaction was performed at $-20{ }^{\circ} \mathrm{C}$.
${ }^{b}$
Reaction was performed at $30{ }^{\circ} \mathrm{C} .{ }^{d}$ Reaction was performed at $0{ }^{\circ} \mathrm{C}$. electrophile and precursor to phenylthiomethyl azide ${ }^{21}$ and diethyl phenylthiomethane phosphonate, an olefination reagent, ${ }^{22}$ can be prepared in nearly quantitative yield. Aryl derivatives (bromomethyl)(4-methylphenyl)sulfane (2k) and (bromomethyl)(4-chlorophenyl)sulfane (2m), used in the preparation of [(p-phenylphenyl)oxy]methyl (POM) protective group ${ }^{23}$ gave $87 \%$ and quantitative yields respectively. Comparatively, previously reported methods delivered $2 \mathbf{k}$ and 2m in $43 \%$ and $75 \%$ yield respectively. ${ }^{11}$ Anisyl thiol $1 \mathbf{r}$ was a challenging substrate, as the bromomethylation was highly exothermic and resulted in a near 1:1 mixture of bromomethylsulfide $2 \mathbf{r}$ and dithioacetal $3 \mathbf{r}$. The yield of $2 \mathbf{r}$ was improved to $4: 1$ ratio, by cooling the reaction mixture to $0{ }^{\circ} \mathrm{C}$. However, purification of $2 \mathbf{r}$ was also problematic as distillation led to partial decomposition. We speculate that integrity of $2 \mathbf{r}$ during preparation and purification is influenced by the neighbouring methoxy function. On the other hand, 2s-u modest yields are attributed to a decrease in S-nucleophilicity caused by the EWG groups. Interestingly, although thiol $1 \mathbf{v}$ bears an EWG at ortho position, methyl 2-((bromomethyl)thio)benzoate $2 \mathbf{v}$ was obtained in excellent yield (85\%).

NMR analyses of a fresh mixture of paraformaldehyde and $\mathrm{HBr} / \mathrm{AcOH}^{24}$ revealed a mixture consisting mainly of a component with an ${ }^{1} \mathrm{H}$-NMR $5.8 \mathrm{ppm}$ signal, correlating to a ${ }^{13} \mathrm{C}$-NMR $68.2 \mathrm{ppm}$ signal (HSQC). This species evolves mainly into two different components: one of them being bis(bromomethyl ether) as determined by a signal at $5.7 \mathrm{ppm}\left({ }^{1} \mathrm{H}-\mathrm{NMR}\right),{ }^{25}$ and bis(bromomethoxy) methane (signals at $5.6 \mathrm{ppm}$ and 5.0 $\mathrm{ppm}){ }^{26}$ The $5.8 \mathrm{ppm}$ signal is presumed to belong to bromomethanol, ${ }^{27}$ which is consumed promptly by the thiol reagent. This is congruent with our observations, since the best results were obtained when the addition sequence consisted in adding the $\mathrm{HBr} / \mathrm{AcOH}$ mixture to premixed thiol and paraformaldehyde (Scheme 2). Equimolar ratios of paraformaldehyde are enough for complete transformation, avoiding formation of potentially highly-toxic bis(bromomethyl ether). ${ }^{28}$ Alkenyl and alkynyl substrates $(\mathbf{2 w}, \mathbf{2 x})$ were incompatible to this method as the bromomethylation procedure led to complex mixtures. Mercaptans featuring attenuated nucleophilicity such as thioacetic or thiobenzoic acids $(\mathbf{2 y}, \mathbf{2 z}), p$-nitrothiophenol (2aa), and 2-mercaptopyridine (2bb) were unsuitable for this methodology.

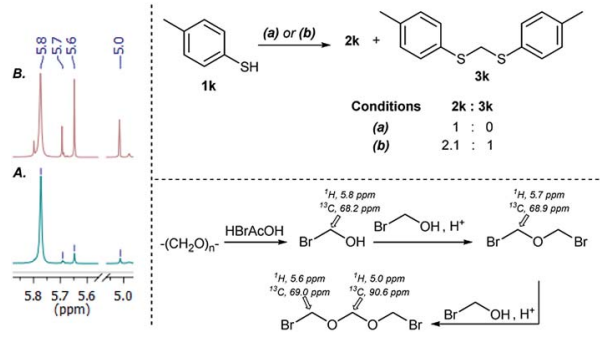

Scheme 2 (A) ${ }^{1} \mathrm{H}$-NMR spectra of paraformaldehyde $+\mathrm{HBr} / \mathrm{AcOH}(<1$ min). (B) ${ }^{1} \mathrm{H}-\mathrm{NMR}$ spectra of paraformaldehyde $+\mathrm{HBr} / \mathrm{AcOH}$ (after 5 min) (left). Conditions: (a) paraformaldehyde addition to $1 \mathrm{k}, 5 \mathrm{~min}$, then $\mathrm{HBr} / \mathrm{AcOH}$ addition, $45 \mathrm{~min}$. (b) $\mathrm{HBr} / \mathrm{AcOH}$ addition to paraformaldehyde, $5 \mathrm{~min}$, then $1 \mathrm{k}, 45 \mathrm{~min}$ (top). Bromomethanol autocondensation decomposition pathway (bottom). 
Attempts to diversify the $\alpha$-alkyl component, found that exclusively highly reactive aldehydes underwent bromoalkylation with thiols (Table 2). Bromoalkylation yields using aldehydes is evidence that reaction efficiency is strongly dependent on the carbonyl reactivity, as bromo(4-nitrobenzylation) or bromoethylation of 4-methylbenzenethiol (1k) using electrophilic 4-nitrobenzaldehyde or acetaldehyde ${ }^{29}$ respectively, feature fair yields compared to the corresponding bromomethylation using paraformaldehyde ( $c f$. entries 1, 3 and 4 ). Interestingly, thiol nucleophilicities have a larger impact in thiol bromoalkylations using aldehydes compared to bromomethylations with paraformaldehyde, as illustrated with superior reaction efficiency when benzyl mercaptan 1a was used instead of $1 \mathbf{k}(c f$. entries 6,7 and 9). Thiol bromoalkylation using ketones had no practical use as dithioketal $3 \mathbf{k} \mathbf{4}$ was the only product when acetone was used as the carbonyl component (entries 10 and 11) and acetophenone yielded a complex mixture (entry 12).

To illustrate the versatility of bromomethyl sulfides as building blocks, we first carried out a polarity reversal through a halogen-metal exchange approach, a relatively rare procedure for the generation of $\alpha$-sulfanylmethyl organometallics. ${ }^{30-32}$ This approach is underdeveloped, probably because of difficulties in synthesizing bromomethylsulfides. ${ }^{33}$ Classically, generation of $\alpha$-sulfanylmethyl organolithiums has been carried out mainly by deprotonation. ${ }^{34}$ However, the deprotonation approach has important drawbacks, such as a substitution side-process that generate thiolates or regioselectivity issues when dialkyl sulfides are deprotonated. ${ }^{35}$ Sequentially exposing (bromomethyl)(cyclohexyl)sulfide (2f) or (bromomethyl)(p-tolyl)sulfide (2k) to $n \mathrm{BuLi}$, generated nucleophilic organolithiums $\mathbf{4 f}$ and $\mathbf{4 k}$, that were quenched by benzaldehyde thus assembling alkylated derivatives $\mathbf{5 f}$ and $\mathbf{5 k}$ in good yields (Scheme 3a). Using

Table 2 Thiol bromoalkylation with selected carbonyl compounds

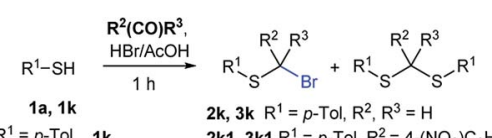

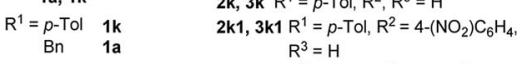

$$
\begin{aligned}
& \text { 2k2, 3k2 } \mathbf{R}^{1}=p \text {-Tol, } \mathbf{R}^{2}=\mathrm{Me}, \mathbf{R}^{3}=\mathrm{H} \\
& 2 \mathbf{k} 3,3 \mathbf{k}^{3} \mathbf{R}^{1}=p-\mathrm{Tol}, \mathrm{R}^{2}=\mathrm{Ph}, \mathbf{R}^{3}=\mathrm{H} \\
& 2 k 4,3 k 4 R^{1}=\rho \text {-Tol, } R^{2}, R^{3}=M \\
& \text { 2a, 3a } R^{1}=B n, R^{2}, R^{3}=H \\
& \text { 2a3, 3a3 } R^{1}=B n, R^{2}=P h, R^{3}=H
\end{aligned}
$$

\begin{tabular}{lllllll}
\hline Entry & $T$ & $\mathrm{R}^{1}-\mathrm{SH}$ & $\mathrm{R}^{2}$ & $\mathrm{R}^{3}$ & 2 yield (\%) & 3 yield (\%) \\
\hline 1 & $\mathrm{rt}$ & $\mathbf{1 k}$ & $\mathrm{H}$ & $\mathrm{H}$ & $\mathbf{2 k}(87 \%)$ & $\mathbf{3 k}-$ \\
2 & $\mathrm{rt}$ & $\mathbf{1 a}$ & $\mathrm{H}$ & $\mathrm{H}$ & $\mathbf{2 a}(91 \%)$ & $\mathbf{3 a}-$ \\
3 & $\mathrm{rt}$ & $\mathbf{1 k}$ & $4-\left(\mathrm{NO}_{2}\right) \mathrm{C}_{6} \mathrm{H}_{4}$ & $\mathrm{H}$ & $\mathbf{2 k 1}(60 \%)$ & $\mathbf{3 k 1}(21 \%)$ \\
$4^{a}$ & $\mathrm{rt}$ & $\mathbf{1 k}$ & $4-\left(\mathrm{NO}_{2}\right) \mathrm{C}_{6} \mathrm{H}_{4}$ & $\mathrm{H}$ & $\mathbf{2 k 1}(67 \%)$ & $\mathbf{3 k 1}(9 \%)$ \\
5 & $\mathrm{rt}$ & $\mathbf{1 k}$ & $\mathrm{Me}$ & $\mathrm{H}$ & $\mathbf{2 k 2}(56 \%)$ & $\mathbf{3 k 2}(36 \%)$ \\
6 & $\mathrm{rt}$ & $\mathbf{1 k}$ & $\mathrm{Ph}$ & $\mathrm{H}$ & $\mathbf{2 k 3}(0 \%)$ & $\mathbf{3 k 3}(69 \%)$ \\
7 & $30{ }^{\circ} \mathrm{C}$ & $\mathbf{1 k}$ & $\mathrm{Ph}$ & $\mathrm{H}$ & $\mathbf{2 k 3}(26 \%)$ & $\mathbf{2 k 3}(69 \%)$ \\
$8^{a}$ & $30{ }^{\circ} \mathrm{C}$ & $\mathbf{1 k}$ & $\mathrm{Ph}$ & $\mathrm{H}$ & $\mathbf{2 k 3}(46 \%)$ & $\mathbf{2 k 3}(29 \%)$ \\
9 & $30{ }^{\circ} \mathrm{C}$ & $\mathbf{1 a}$ & $\mathrm{Ph}$ & $\mathrm{H}$ & $\mathbf{2 a 3}(61 \%)$ & $\mathbf{3 a 3}(19 \%)$ \\
10 & $\mathrm{rt}$ & $\mathbf{1 k}$ & $\mathrm{Me}$ & $\mathrm{Me}$ & - & $\mathbf{3 k 4}(52 \%)$ \\
11 & $40{ }^{\circ} \mathrm{C}$ & $\mathbf{1 k}$ & $\mathrm{Me}$ & $\mathrm{Me}$ & - & $3 \mathbf{k} 4(29 \%)$ \\
12 & $40{ }^{\circ} \mathrm{C}$ & $\mathbf{1 k}$ & $\mathrm{Ph}$ & $\mathrm{Me}$ & $\mathrm{Complex} \mathrm{mixture}$
\end{tabular}

${ }^{a}$ Reaction time $16 \mathrm{~h}$.

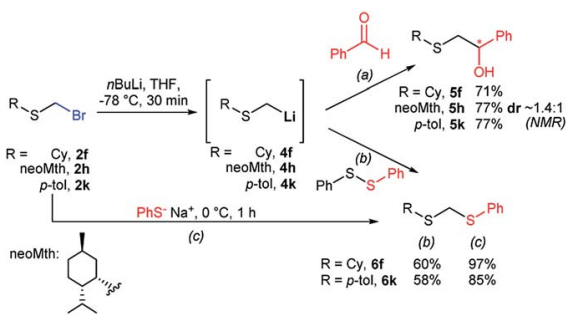

Scheme $3 \mathrm{Br}$-Li exchanges on bromomethyl sulfides for the generation of nucleophilic sulfanylmethyllithiums: (a) $\beta$-hydroxysulfide syntheses, (b) unsymmetrical dithioacetal synthesis. (c) Alternate unsymmetrical dithioacetal synthesis by exploiting bromomethyl sulfides (2) electrophilicity.

(+)-neomenthanethiol bromomethyl sulfide derivative (2h) for the bromo-lithium exchange and benzaldehyde in the electrophilic quench, generated $\beta$-hydroxysulfide $\mathbf{5 h}$ in good yield albeit low diastereoselectivity ( $c a .1 .4: 1$ ). This constitutes a novel approach for the application of sulfenyl methyllithium organometallics for the access of $\beta$-hydroxysulfides, valuable intermediates or fragments of natural products and biologically relevant compounds, usually prepared under acidic media or free radical oxidative conditions. ${ }^{36}$ On the other hand, preparation methods of mixed or unsymmetrical dithioacetals are scarce, ${ }^{37}$ some of them displaying selectivity limitations. ${ }^{38}$ Similar bromo-lithium exchange/functionalization procedures were also carried out on probes $2 \mathbf{f}$ and $2 \mathbf{k}$ using diphenyldisulfide as electrophile, ${ }^{39}$ delivering mixed thioacetals $\mathbf{6 f}$ and $\mathbf{6 k}$ respectively also with good yields (Scheme $3 \mathrm{~b}$ ). The exceptional electrophilicity of bromomethyl sulfides $2 \mathbf{f}$ and $\mathbf{2 k}$, also enabled the access to mixed thioacetals $\mathbf{6} \mathbf{f}$ and $\mathbf{6 k}$ by simple exposure to sodium thiophenolate, ${ }^{40,41}$ thus demonstrating the versatility of bromomethyl sulfides either as electrophiles or nucleophiles after umpolung.

To our knowledge, bromomethyl sulfides 2 have not been exploited for $\mathrm{C}-\mathrm{C}$ bond construction through free radical chemistry. As far as we know, there is a single reference to an unrealized effort attempting an intramolecular free radical cyclization of an unavailable alkenyl bromomethylsulfide. ${ }^{14,42}$ Although our method unfortunately was not compatible with the direct preparation of alkenylsulfide bromomethyl derivatives (see Table 1), we could demonstrate exceptional reactivity of $\alpha$-thiomethyl radical $7 \mathbf{k}$ (generated from $2 \mathbf{k}$ ), towards $(\mathrm{TMS})_{3} \mathrm{SiH}$ reduction, ${ }^{43}$ thus generating thioether $\mathbf{8 k}$ (Scheme 4a). On the other hand, $\mathrm{Et}_{3} \mathrm{~B}$ initiated ${ }^{44}$ additions of nucleophilic radicals ${ }^{40,45} 7 \mathbf{f}$ and $7 \mathbf{k}$ on radical acceptors acrylonitrile and methyl acrylate led to the

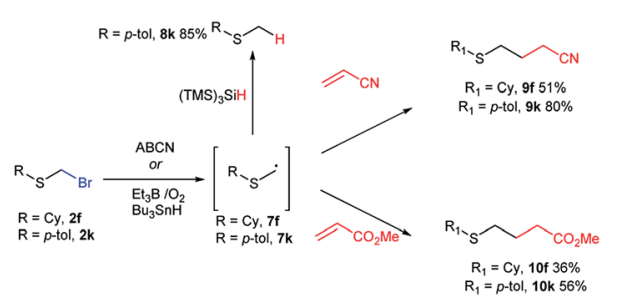

Scheme 4 Unprecedented generation of $\alpha$-thiomethyl free radicals from bromomethyl sulfides and their reduction and addition to acrylonitrile and methyl acrylate. 
generation of $\gamma$-functionalized sulfides $9 \mathbf{f}, 9 \mathbf{k}, \mathbf{1 0 f}$ and $10 \mathbf{k}$ (Scheme $4 \mathrm{~b}$ ). This constitutes a novel approach for the synthesis of $\gamma$-sulfanyl butanenitriles and esters, as an alternative to the thiol-ene reaction approach, ${ }^{\mathbf{4 6}}$ and establishes bromomethyl sulfides as a new entry on the family of monothiomethyl radical sources. $^{47}$

\section{Conclusions}

Development of synthetic methods based on bromomethyl sulfides has been limited mainly by their ambiguous availability, as a consequence of methods lacking selectivity, efficiency, and perilous set-ups. We have developed a simple and high yielding method for thiol bromomethylation, that involves operational simplicity, and minimizes operational risk. The method has broad scope and good functional group tolerance but is unsuitable for low-nucleophilicity mercaptans. The bromomethylating reagent is suspected to be bromomethanol, obtained stoichiometrically and efficiently captured by thiols, thus preventing the formation of undesired toxic species such as bis(bromomethyl)ether. We re-disclosed the applicability of bromomethyl sulfides as precursors of lithiated organometallics and performed unprecedented free radical additions, that support the usefulness of these building blocks. More synthetic applications and derivatizations of bromomethyl sulfides are currently being developed in our laboratories.

\section{Conflicts of interest}

There are no conflicts to declare.

\section{Acknowledgements}

This work was supported by Conacyt (Mexico) [CB-241455]. C. S.-C. is grateful with Conacyt for a PhD scholarship [340614] and E. P. also thanks Conacyt for a PDF fellowship [217966]. We thank Teresa Cortez Picasso, Victor González Díaz and María Luisa Rodríguez Pérez (Cinvestav), for their assistance with NMR experiments, Géiser Cuellar Rivera (Cinvestav) for his assistance with HRMS measurements, and Ana Lilia Carrasco González (Cinvestav) for her help on performing selected elemental microanalyses. Dr Luis A. Polindara (UNAM) is acknowledged for additional DART-MS and HRMS measurements. We also thank Allen Chao for helpful suggestions on the manuscript and María Martínez-Montoya for assisting C. S. C. on additional experiments.

\section{Notes and references}

1 Selected literature: (a) D. Seyferth, J. K. Heeren, G. Singh, S. O. Grim and W. B. Hughes, J. Organomet. Chem., 1966, 5, 267-274; (b) B. H. Lipshutz and J. J. Pegram, Tetrahedron Lett., 1980, 21, 3343-3346; (c) J. E. Baldwin, R. M. Adlington and J. Robertson, Tetrahedron, 1989, 45, 909-922; (d) R. Hartung, G. Golz, S. Schlaf, G. Silvennoinen, K. Polborn, P. Mayer and H. Pfaendler, Synthesis, 2009, 495-501.
2 Recent literature: (a) L. C. Dias and M. A. B. Ferreira, J. Org. Chem., 2012, 77, 4046-4062; (b) N. Veerasamy, E. C. Carlson, N. D. Collett, M. Saha and R. G. Carter, J. Org. Chem., 2013, 78, 4779-4800; (c) C. De Monte, S. Carradori, B. Bizzarri, A. Bolasco, F. Caprara, A. Mollica, D. Rivanera, E. Mari, A. Zicari, A. Akdemir and D. Secci, Eur. J. Med. Chem., 2016, 107, 82-96; (d) A. P. Green, S. Hardy and E. J. Thomas, Org. Biomol. Chem., 2017, 15, 9475-9496; (e) R.-Y. Liu, Z.-F. Peng and X.-N. Hou, New J. Chem., 2017, 41, 7626-7633.

3 (a) C. T. Goralski and G. A. Burk, J. Org. Chem., 1977, 42, 3094-3096; (b) N. Ono, H. Miyake, T. Saito and A. Kaji, Synthesis, 1980, 952-953.

4 Selected literature: (a) H. Böhme, Ber. Dtsch. Chem. Ges. B, 1936, 69, 1610-1615; (b) T. Miyamoto and I. Yamamoto, Agric. Biol. Chem., 1980, 44, 2581-2586; (c) D. Enders, S. von Berg, B. Jandeleit, J. Cheng and W. R. Roush, Org. Synth., 2002, 78, 169; (d) K. K. Laali, in Encyclopedia of Reagents for Organic Synthesis, John Wiley \& Sons, Ltd, Chichester, UK, 2001, pp. 2-4, and references included within.

5 (a) H. Böhme, H. Fischer and R. Frank, Justus Liebigs Ann. Chem., 1949, 563, 54-72. See also:; (b) D. A. Evans, D. J. Mathre and W. L. Scott, J. Org. Chem., 1985, 50, 18301835.

6 (a) D. Seyferth, Organometallics, 2006, 25, 2-24; (b) P. Knochel, W. Dohle, N. Gommermann, F. F. Kneisel, F. Kopp, T. Korn, I. Sapountzis and V. A. Vu, Angew. Chem., Int. Ed., 2003, 42, 4302-4320.

7 (a) L. W. Fancher, Ger. Pat., 1112 735, 1961Chem. Abstr., 1962, 56, 11499c; (b) H. J. Reich, C. P. Jasperse and J. M. Renga, J. Org. Chem., 1986, 51, 2981-2988.

8 Dibromomethane is an ozone depleting substance which use has been discouraged: Y. Yokouchi, T. Saito and H. Mukai, J. Atmos. Chem., 2017, 1-10, and references included within.

9 (a) X. Zhu, K. Pachamuthu and R. R. Schmidt, Org. Lett., 2004, 6, 1083-1085; (b) Q. Xia, Y. J. Wen, H. Wang, Y. F. Li and H. H. Xu, J. Agric. Food Chem., 2014, 62, 11037-11046; (c) M. Esseffar, M. El Messaoudi, R. Jalal, L. R. Domingo and M. J. Aurell, J. Phys. Org. Chem., 2008, 21, 457-463.

10 (a) F. Marty, E. Bollens, E. Rouvier and A. Cambon, J. Fluorine Chem., 1990, 48, 239-248; (b) L. Massi, F. Guittard, R. Levy and S. Géribaldi, Eur. J. Med. Chem., 2009, 44, 1615-1622; (c) G. H. Phillipps, E. J. Bailey, B. M. Bain, R. A. Borella, J. B. Buckton, J. C. Clark, A. E. Doherty, A. F. English and H. Fazakerley, J. Med. Chem., 1994, 37, 3717-3729; (d) H. Trabelsi, M. A. Jouani and A. Cambon, J. Fluorine Chem., 1996, 79, 27-31; (e) H. Trabelsi, F. Szönyi and S. Geribaldi, J. Fluorine Chem., 2001, 107, 177-181.

11 H. Ishibashi, K. Maruyama and K. Minami, J. Chem. Soc., Chem. Commun., 1987, 53, 1443-1445.

12 (a) C. Silva-Cuevas, C. Perez-Arrieta, L. A. Polindara-García and J. A. Lujan-Montelongo, Tetrahedron Lett., 2017, 58, 2244-2247; (b) J. A. Lujan-Montelongo, A. O. Estevez and F. F. Fleming, Eur. J. Org. Chem., 2015, 1602-1605.

13 H. J. Reich and J. M. Renga, J. Chem. Soc., Chem. Commun., 1974, 135-136. 
14 Dibromomethane condensation with thiols is often problematic, see: E. W. Della and S. D. Graney, J. Org. Chem., 2004, 69, 3824-3835.

15 Selected literature: (a) D. Ben-Ishai, J. Org. Chem., 1954, 19, 62-66; (b) R. C. Desai, R. P. Farrell, G.-H. Kuo and D. J. Hlasta, Synlett, 1994, 933-934; (c) C. Anderson, S. S. Hadida-Ruah, J. M. C. Golec, B. Zhang, B. J. Littler, A. Keshavarz-Shokri, T. E. Alcacio and D. T. Belmont, US Pat. 0376295 A1, 2016.

16 J. J. Court, T. A. Lessen and D. J. Hlasta, Synlett, 1995, 423424.

17 A. van der Made, in Encyclopedia of Reagents for Organic Synthesis, John Wiley \& Sons, Ltd, Chichester, UK, 2001, pp. 1-2.

18 We believe that our simple isolation procedure is key for optimal performance, since adopting aqueous workups gave us inconsistent results (variable amounts of dithioacetal products).

19 G. Bashiardes and S. G. Davies, Tetrahedron Lett., 1987, 28, 5563-5564.

20 L. Massi, F. Guittard, R. Levy and S. Géribaldi, Eur. J. Med. Chem., 2009, 44, 1615-1622.

21 (a) D. Dou, G. He, Y. Li, Z. Lai, L. Wei, K. R. Alliston, G. H. Lushington, D. M. Eichhorn and W. C. Groutas, Bioorg. Med. Chem., 2010, 18, 1093-1102; (b) K. C. Tiew, D. Dou, T. Teramoto, H. Lai, K. R. Alliston, G. H. Lushington, R. Padmanabhan and W. C. Groutas, Bioorg. Med. Chem., 2012, 20, 1213-1221; (c) E. J. Hennessy, M. Cornebise, L. Gingipalli, T. Grebe, S. Hande, V. Hoesch, H. Huynh, S. Throner, J. Varnes and Y. Wu, Tetrahedron Lett., 2017, 58, 1709-1713.

22 D. J. Fairfax, PhD thesis, University of London, 1991.

23 K. S. Fors, J. R. Gage, R. F. Heier, R. G. Kelly, W. R. Perrault and N. Wicnienski, J. Org. Chem., 1998, 63, 7348-7356.

24 Analysed immediately after mixing paraformaldehyde and $\mathrm{HBr} / \mathrm{AcOH}$.

$25 \mathrm{~A}{ }^{13} \mathrm{C}$-NMR signal at 68.9 was assigned to bis(bromomethyl) ether as judged by a HSQC experiment.

26 Integrals of signals at 5.6 and $5.0 \mathrm{ppm}$ are congruent with compound identity ( $2: 1$ ratio). $5.6 \mathrm{ppm}$ signal correlates to a ${ }^{13} \mathrm{C}$ signal at $69.0 \mathrm{ppm}$ and signal at 5.0 correlates with a ${ }^{13} \mathrm{C}$ signal at $90.6 \mathrm{ppm}$.

27 As judged by its chemical shift compared to the other species (more unshielded protons). No acetyl signals besides $\mathrm{AcOH}$ related were found. After extended times 5-24 h in $\mathrm{CDCl}_{3}$, bromomethanol signal in sample decreased substantially, as the others increased.

28 Following a strict measurement of the reagents, we couldn't find evidence of formation of bis(bromomethyl)ether by ${ }^{1} \mathrm{H}$ NMR (see ref. 17). However, extremely caution is mandatory as bis(halomethyl)ethers are highly toxic and carcinogenic: R. T. Drew, S. Laskin, M. Kuschner and N. Nelson, Arch. Environ. Occup. Health, 1975, 30, 61-69.

29 Formaldehyde and p-nitrobenzaldehyde are well-known to be superior electrophiles experimentally: (a) M. Regitz and G. Maas in, Diazo Compounds Properties and Synthesis, Academic Press, Inc., Orlando, 1986, ch. 14, p. 472S; and computationally; (b) Private communication with A. U. Orozco-Valencia and A. Vela. See also: A. U. OrozcoValencia, J. L. Gázquez and A. Vela, J. Phys. Chem. A, 2017, 121, 4019-4029.

30 Selected works by Krief and others cite an unpublished exchange approach for the generation of lithium derivatives from bromomethyl sulfides. However, as far as we know, such lithiation method was never published. See: (a) L. Wartski, M. El Bouz, J. Seyden-Penne, W. Dumont and A. Krief, Tetrahedron Lett., 1979, 20, 1543-1546; (b) J. N. Denis, W. Dumont and A. Krief, Tetrahedron Lett., 1979, 20, 4111-4112; (c) J. J. Zuckerman, in Inorganic Reactions and Methods, ed. J. J. Zuckermam and A. P. Hagen, VCH, Weinheim, 1988, vol. 11, ch. 5.5, pp. 107-129.

31 Formation of thiomethylmanganese organometallics have been reported by a I-Mn exchange protocol: M. Hojo, R. Sakuragi, Y. Murakami, Y. Baba and A. Hosomi, Organometallics, 2000, 19, 4941-4943.

32 For alternative methods for the generation of sulfenylstabilized carbanions see: $\mathrm{C}$. $\mathrm{Ni}$ and $\mathrm{J}$. $\mathrm{Hu}$, in Comprehensive Organic Synthesis II, ed. P. Knochel and G. A. Molander, Elsevier, 2014, vol. 1, pp. 395-423, and references included within.

33 A. Krief, Tetrahedron, 1980, 36, 2531-2640.

34 Selected literature: (a) H. Gilman and F. J. Webb, J. Am. Chem. Soc., 1940, 62, 987-988; (b) E. J. Corey and D. Seebach, J. Org. Chem., 1966, 31, 4097-4099; (c) E. J. Corey and M. Jautelat, Tetrahedron Lett., 1968, 9, 5787-5788; (d) I. Kuwajima, S. Sato and Y. Kurata, Tetrahedron Lett., 1972, 13, 737-739; (e) A. I. Meyers and M. E. Ford, J. Org. Chem., 1976, 41, 1735-1742; (f) Y. Liu and R. S. Glass, Tetrahedron Lett., 1997, 38, 8615-8618; $(g)$ M. Linnert, C. Bruhn, T. Rüffer, H. Schmidt and D. Steinborn, Organometallics, 2004, 23, 3668-3673.

35 D. J. Peterson, J. Org. Chem., 1967, 32, 1717-1720.

36 (a) H. Wang, Q. Lu, C. Qian, C. Liu, W. Liu, K. Chen and A. Lei, Angew. Chem., Int. Ed., 2016, 55, 1094-1097; (b) A. K. Singh, R. Chawla, T. Keshari, V. K. Yadav and L. D. S. Yadav, Org. Biomol. Chem., 2014, 12, 8550-8554; (c) C. Huo, Y. Wang, Y. Yuan, F. Chen and J. Tang, Chem. Commun., 2016, 52, 7233-7236; (d) N. Azizi and M. Edrisi, Tetrahedron Lett., 2016, 57, 525-528; (e) S. R. Lanke and B. M. Bhanage, Catal. Commun., 2013, 41, 29-33.

37 (a) J. Y. Gauthier, T. Henien, L. Lo, M. Thérien and R. N. Young, Tetrahedron Lett., 1988, 29, 6729-6732; (b) M. Thérien, J. Gauthier and R. Young, Tetrahedron Lett., 1988, 29, 6733-6736; (c) H. E. Morton and Y. Guindon, J. Org. Chem., 1985, 50, 5379-5382; (d) J. M. McNamara, J. L. Leazer, M. Bhupathy, J. S. Amato, R. A. Reamer, P. J. Reider and E. J. J. Grabowski, J. Org. Chem., 1989, 54, 3718-3721.

38 (a) B. Roy, D. Sengupta and B. Basu, Tetrahedron Lett., 2014, 55, 6596-6600; (b) X. Ling, S. Zhang, P. Shao, P. Wang, X. Ma and M. Bai, Tetrahedron Lett., 2015, 56, 5242-5244.

39 Although sulfenylation by electrophilic quench of anionic methylene groups using disulfides is well stablished, this is the first time that methylsulfide organometallics are 
used for this purpose. See:(a) M. Mikolajczyk, J. Drabowicz and P. Kielbasinski, Formation of C-S Bonds, in HoubenWeyl Methods of Organic Chemistry. Stereoselective Synthesis, ed. G. Helmchen, R. W. Hoffmann, J. Mulzer and E. Schaumann, Georg Thieme Verlag, 1995, vol. E 21e, pp. 5040-5041; (b) T. Takeda and A. Tsubouchi, Product Subclass 1: Acyclic S,S-Acetals, in Science of Synthesis, ed. J. Otera, Thieme, 2007, vol. 30, pp. 149-155, and references included within.

40 Related nucleophilic displacements for the preparation of symmetric dithioacetals $(a)$ Y. M. Tsai, F. C. Chang, J. Huang and C. L. Shiu, Tetrahedron Lett., 1989, 30, 21212124, and unsymmetric dithioacetals; $(b)$ M. B. Green and W. L. Jenkins, J. Sci. Food Agric., 1958, 9, 536-539.

41 R. Jorritsma, H. Steinberg and T. J. de Boer, Recl. Trav. Chim. Pays-Bas, 2010, 101, 288-298.

42 For related $\alpha$-sulfenylalkyl radical generation see: Y. M. Tsai, F. C. Chang, J. Huang, C. L. Shiu, C. L. Kao and J. S. Liu, Tetrahedron, 1997, 53, 4291-4308.

43 (a) C. Chatgilialoglu, D. Griller and M. Lesage, J. Org. Chem., 1988, 53, 3641-3642; (b) C. Chatgilialoglu and V. I. Timokhin, in Advances in Organometallic Chemistry, 2008, vol. 57, pp. 117-181; (c) C. Chatgilialoglu and J. Lalevée, Molecules, 2012, 17, 527-555.
44 (a) C. Ollivier and P. Renaud, Chem. Rev., 2001, 101, 34153434; (b) Y. Yamamoto, T. Yoshimitsu, J. L. Wood and L. N. Schacherer, in Encyclopedia of Reagents for Organic Synthesis, John Wiley \& Sons, Ltd, Chichester, UK, 2007, vol. 1, pp. 1-6; and references included within.

45 F. De Vleeschouwer, V. Van Speybroeck, M. Waroquier, P. Geerlings and F. De Proft, Org. Lett., 2007, 9, 2720-2724.

46 (a) J. W. Lynn, R. L. Roberts and J. R. Kilsheimer, J. Org. Chem., 1961, 26, 4300-4303; (b) P. Caspari, F. A. Nüesch, A. Neels and D. M. Opris, RSC Adv., 2016, 6, 98059-98065, and references included within.

47 (a) E. Hasegawa, M. A. Brumfield, P. S. Mariano and U. C. Yoon, J. Org. Chem., 1988, 53, 5435-5442; (b) U. Chan Yoon, H.-J. Kim and P. S. Mariano, Heterocycles, 1989, 29, 1041; (c) U. C. Yoon, Y. C. Kim, J. J. Choi, D. U. Kim, P. S. Mariano, I. S. Cho and Y. T. Jeon, J. Org. Chem., 1992, 57, 1422-1428; (d) T. Ikeno, M. Harada, N. Arai and K. Narasaka, Chem. Lett., 1997, 26, 169-170; (e) Y. Li, K. Miyazawa, T. Koike and M. Akita, Org. Chem. Front., 2015, 2, 319-323; $(f)$ N. El Achi, M. Penhoat, Y. Bakkour, C. Rolando and L. Chausset-Boissarie, Eur. J. Org. Chem., 2016, 4284-4288. 